The

Connecticut

Agricultural

Experiment

Station,

A Computer Model

of the Gypsy Moth

and its Fungal

New Haven

Pathogen

BY RONALD M. WESELOH

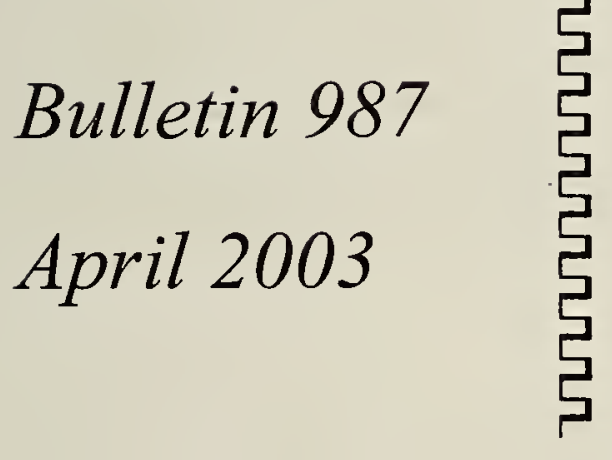




\begin{abstract}
A one-host generation computer model, with a time-step of 1 day, has been developed to simulate the interaction between the very effective fungal pathogen, Entomophaga maimaiga, and its host, the gypsy moth. This publication describes the structure of the validated model, the kinds of model inputs needed and the outputs produced, and gives examples of model results. The model can be used to construct scenarios of future gypsy moth-fungus interactions and to evaluate the effectiveness of the fungus as a biological control agent.
\end{abstract}




\title{
A Computer Model of the Gypsy Moth and its Fungal Pathogen
}

\author{
By Ronald M. Weseloh
}

The gypsy moth fungal pathogen, Entomophaga maimaiga, was first found to be established in North America in 1989 (Andreadis and Weseloh 1990), and positively identified as a species from Japan (Hajek et al. 1990). Since 1989 , the fungus has significantly suppressed the gypsy moth in the generally infested areas of North America. Numerous scenarios have been proposed for how it became established (Hajek et al. 1995), but we probably will never know for sure.

Fortunately, E. maimaiga is a very specific natural enemy, attacking only the gypsy moth and a few closely related Lymantriidae. Many aspects of its biology, ecology, and epidemiology have been reviewed by Hajek (1999). The fungus passes the winter as spherical resting spores in forest soil. In spring, at about the time when gypsy moth larvae are hatching, and if the soil is moist enough, some spores germinate to produce long germ tubes that form pear-shaped primary conidia at the tip. These conidia are dispersed in the air and if they contact a gypsy moth larva, will break through the skin to infect the caterpillar.

The fungus develops rapidly depending on temperature, eventually killing the larva. Then if relative humidity is close to $100 \%$, the fungus will sporulate through the caterpiliar's integument and produce thousands of secondary conidia, which are very similar to primary conidia. These disperse in the air to infect other larvae. The entire process of sporulation, successful air transport, and infection depends on humidities remaining near $100 \%$. Near the end of larval development, the fungus in many dead infected larvae form thousands of resting spores rather than conidia. These cadavers then weather off tree trunks and release spores into the top soil layers where they over winter. Weseloh and Andreadis (2002) have shown that resting spores may remain viable in soil for up to 10 years, thus providing a very important multi-year reservoir of infection.
Proper weather conditions are very important for the fungus to be effective. Moist soil during the gypsy moth larval season and adequate rainfall at the times of conidial sporulation must occur for the fungus to infect larvae. The number of resting spores in the soil (resting spore load) and the number of gypsy moths available for infection probably also influence fungus activity. Using these inputs, colleagues and 1 have developed a computer model that simulates the infection, growth, and death of the host and pathogen over a single season (Weseloh, et al. 1993, Weseloh 1999, 2002). This model was validated with independent data in 2002 (Weseloh, submitted). Such a model should be useful in exploring the interaction between the gypsy moth and E. maimaiga, and might even be helpful in predicting seasonal effectiveness of the fungus if some indication of future weather conditions can be obtained. To encourage its use among forest managers, I have developed what 1 hope is an easily used version of the model.

This publication brings together information about the workings of the model and the kinds of inputs necessary for running the user-friendly version. The latter uses less exact estimates for input data than does the validated model, so 1 also compare outputs of the two versions. The model is available on the Internet (at http://www.caes.state.ct.us) and can be downloaded and run with example inputs or your own inputs. A source file in Borland Turbo $\mathrm{C}++$ is also provided for anyone who wishes to make modifications to the program.

Structure of the Model. The model was developed over a number of years and reported in a series of publications (Weseloh, et al. 1993, Weseloh 1999, 2002). These publications should be consulted for a description of model development and justification of equations and parameter values used. Only the current model will be described here. The model simulates the interaction between $E$. maimaiga 
and the gypsy moth during one season for the period of time that gypsy moth larvae are available. The time step is one day. Larvae are assumed to hatch over a period of 16 days, starting at an assigned first hatch date, such that the number hatching each subsequent day varies according to a normal distribution with mean of 7.5 days after the start date and standard deviation of 2.5 days. The larvae that hatch during a given day are assumed to be one cohort, and all develop at the same rate. Cohorts develop according to a degree-day model with threshold temperature of $12 \mathrm{C}(54 \mathrm{~F})$. They change instars at the following degree-days (dd) after hatch: (1-2 instar, $35 \mathrm{dd}$; $2-3$ instar, $70 \mathrm{dd}$; $3-4$ instar, $105 \mathrm{dd}$; $4-5$ instar, $150 \mathrm{dd} ;>5$ instar, $240 \mathrm{dd}$ ).

Resting spores germinate when the soil is moist enough. The probability of infection of one larva in a cohort by resting spores $\left(P_{r}\right)$ on a day is:

$$
P_{r}=0.0035 R[\sin (0.01431 M)]^{2}
$$

where $R$ is the percent of larvae infected in a soil bioassay (see inputs, below), and $M$ is a forest moisture index defined as the total amount of rain accumulated over the present day and the last 4 days, with no more than $10 \mathrm{~mm}$ ( 0.4 inches) of rain allowed per day. At the beginning of the season before secondary conidia are produced, the number of larvae infected from a given cohort on a given date is determined by multiplying $P_{r}$ by the number of larvae in the cohort. These infected larvae then form a new infected cohort in which the fungus develops at a rate $(r)$ according to temperature $(T)$ between 7.5 to $26 \mathrm{C}(45-79 \mathrm{~F})$ :

$$
r=-0.162+0.032 T-0.000752 T^{2}
$$

This equation was estimated from data by Hajek, et al. (1993). From the rates for each day, the model determines the date when larvae in the infected cohort die.

When an infected cohort dies, the number of conidia produced per $\mathrm{m}^{3}$ of forest space (i.e., the volume from top of canopy to ground) per day (c) varies with the number of larvae in the cohort $\left(N_{i}\right)$, the cohort instar, the proportion of the day for which humidity is above $98 \%(H)$, and the number of days after death $(d)$ :

$$
\begin{array}{r}
\text { Instar 2: } c=11639 N_{i} H \exp (-0.36 d) \\
\text { Instar 3: } c=24542 N_{i} H \exp (-0.763 d) \\
\text { Instar 4: } c=32832 N_{i} H \exp (-0.491 d) \\
\text { Instar 5+: } c=204875 N_{i} H \exp (-0.859 d)
\end{array}
$$

If $d$ is greater than 8 days, then $\mathrm{c}=0$. Instars 5 and 6 are treated as one instar $(5+)$ because the equation for 6 th instars was similar to the one for 5 th instars and only female caterpillars generally have 6 instars.

Infection of a cohort by secondary conidia depends on conidial concentration $(c)$ as determined above, and a size factor for the larvae in a cohort $(s)$

The size factor is determined as a function of the degreedays of development $(D)$ of the healthy cohort from hatch:

$$
\mathrm{s}=D^{2} /\left(91613.9+0.6798 D^{2}\right)
$$

Then the probability, $P_{c}$, that one larva in a cohort will become infected when there are $c$ conidia in a $\mathrm{m}^{3}$ volume is:

$$
P_{c}=1-(1-0.002 s)^{c}
$$

where $s$ is the above-mentioned size factor.

The total probability of infection $\left(P_{\eta}\right)$ from both resting spores $\left(P_{r}\right)$ and conidia $\left(P_{c}\right)$ for a larva in a cohort is then:

$$
P_{r}=P_{r}+P_{c}-P_{r} P_{c}
$$

because the two probabilities are independent. The model multiplies this total probability by the number of healthy caterpillars in a cohort to give the number of larvae in a new, infected cohort.

Model Inputs. The model inputs are daily maximum and minimum temperatures in degrees Fahrenheit and daily rainfall in inches and hundredths of inches from the time that gypsy moth larvae begin to hatch to the time when about half of them have pupated. In Connecticut, this is from about May I to July I. These data can be obtained from a nearby weather station, but because rainfall is often spatially localized, it is best if daily rainfall is measured in the location of interest. These data are adequate for determining degree-days of development using the modified sine-wave method of Allen (1976) for interpolating temperatures within a day from daily maximum and minimum values. The proportion of a particular day having humidities above $98 \%$ $(H)$, which is needed to determine production rate of conidia, is estimated from daily rainfall on the present day $\left(r_{0}\right.$, given in $\mathrm{mm})$, and the last 3 days $\left(r_{l}, r_{2}, r_{3}\right)$, and the maximum and minimum temperatures for the present day (in degrees $\mathrm{C}$ )

$\left(T_{x}, T_{n}\right.$, respectively) as: $H=0.322998+0.1$ sqrt $\left(1.0 r_{0}+0.5\right.$ $\left.r_{1}+0.25 r_{2}+0.125 r_{3}\right)-0.07 \operatorname{sqrt}\left(T_{x}-T_{n}\right)$

This equation was obtained after a good deal of effort to relate rainfall and temperature to $H$, and the fit is only approximate. A better solution is to monitor actual humidity levels at the site with a data logger capable of taking measurements every 10 minutes or so. The validated version of the program uses temperature, rainfall, and humidity records with such resolution and is available from the author (Ronald.Weseloh@po.state.ct.us).

Also necessary as model inputs are some measure of resting spore load and gypsy moth larval density. Resting spore load in the soil is best measured by collecting soil from just under the litter layer near the trunks of gypsy moth favored food trees, such as oaks, mixing these together for any one plot, and carrying back a sample to the laboratory. Forty $\mathrm{ml}$ sub-samples of the soil are placed in a $2.5 \times 14.0$ $\mathrm{cm}$ plastic Petri dish with five disks of $12.5 \mathrm{~cm}$ diam filter paper in the bottom and drenched with distilled water. After holding for $\mathrm{I}$ week at $17 \mathrm{C}$ and $15 \mathrm{hr}$ light per day, 25 2nd or 3 rd instar gypsy moths are placed on top of a screen disk placed over the soil and held with the soil for $24 \mathrm{hr}$. The larvae are then reared individually in $40 \mathrm{ml}$ clear plastic cups filled $1 / 4$ full with gypsy moth diet (Southland Products, Lake Village, Arkansas) and held for 2 weeks. The percentage that 
Table 1. Comparison of seasonal mortality between the detailed, validated fungus model and the current, user- friendly version for various areas sampled in 2001 and 2002.

Year

2001

2001

2001

2002
Location

Harwinton, CT

Rhode Island

Mansfield Hollow, CT

Mansfield Hollow, CT

$\begin{array}{cr}\text { No. Plots } & \text { acre } \\ 2 & 226 \\ 2 & 2343 \\ 6 & 2143 \\ 7 & 261\end{array}$

261

Avg. years since
defoliation
$>10$
I
5.9
5.2

5.2
Seasonal Mortality predictions

$\begin{array}{cc}\text { Validated } & \text { Current } \\ \text { model } \% & \text { model } \% \\ 99.2 & 9 \\ 92.0 & 100 \\ 97.7 & 98 \\ 62.3 & 68\end{array}$

die from fungus is a measure of resting spore load in the soil and is used as a model input.

The above procedure is too involved for common use, so the current model version uses a surrogate measure of resting spore load based on the number of years since defoliation last occurred. Weseloh and Andreadis (2002) determined that resting spore viability declines linearly over 10 years. Thus, the model assumes that resting spore load can be expressed as the greater of $1.0 \%$ or $55.0 \%-5 y$, when $y$ is the number of years since the last defoliation occurred at the site of interest.

The model input used for gypsy moth density in the validated model is the average of the number of gypsy moth larvae found on 25, 30-cm (12 inches) terminal branches of favored food plants (such as oaks or witch hazel) that can be reached from the ground. This count is made about 3 weeks after larvae have hatched. The current model assumes that such terminal counts can be derived from egg mass counts/acre by multiplying by 0.0007512 (Weseloh 2003). Thus, the input to the model is the number of egg masses/acre.

In the course of developing and validating the model, 1 found that local dispersal of secondary conidia must be taken into account if output is to be accurate. Specifically, the validated model works much better if the number of conidia produced each day from several plots within about a $2 \mathrm{~km}$ (1.2 miles) radius are averaged before being used to infect healthy cohorts (Weseloh 2002). Within such a small area, it is likely that weather conditions, even rainfall, will be homogeneous enough for model purposes. But resting spore load in the soil and gypsy moth larval density can vary by orders of magnitude over these distances (personal observations). Thus, it is necessary to obtain defoliation history and egg mass density for five to ten plots within about a mile of the location of interest. The values are then averaged and used as inputs to the model.

Model Outputs. The model generates two outputs: (1) the percent of living larvae infected with the fungus during each day of the season, and (2) the proportion of hatched larvae that are healthy on each day. The first output can be directly compared to actual percent infection prevalence in the forest as sampled by collecting and rearing larvae. The second output is most useful when trying to evaluate the impact of the fungus on a gypsy moth population. The program always plots these values in a graph when an analysis is done and displays the overall seasonal fungus-induced gypsy moth mortality. If you name an output file, the outputs for each day are saved to a text file that can be imported into a statistical program or spreadsheet for further analysis.

Comparison of Model Results. In 2001 and 2002, I had available high-quality input data from data-loggers in plots (Hobo Pro Rh/Temp, Onset Computer Corp, Pocasset, MA) that recorded temperature and relative humidity every 10 minutes, and a data-logging rain gauge (Onset) that recorded precipitation. Also, resting spore loads from bioassay results and terminal counts were available both years. Thus, 1 had data suitable for using the validated model and from it I obtained values of average seasonal mortality in four different areas, three in 2001 and one in 2002. These estimates are compared to estimates for the same areas using the current, user-friendly version (Table 1).

Only for the Harwinton area in 2001 were the results for the two models substantially different. Part of the reason is that actual resting spore load was much higher in this area than was estimated by defoliation history. However, even when I assumed defoliation had occurred the year before, seasonal mortality in Harwinton for the current model only increased to $58 \%$. The Harwinton result shows the inadvisability of using data from only a few locations (in this case, two).

Future Uses. The current version of the model should be relatively easy to use because the required biological input data (defoliation and egg mass records) are often readily available. Fortunately, the user-friendly version often approaches the accuracy of the validated version. However, weather information is also needed for input, and because weather cannot be predicted in any precise way, neither can future fungus effects. But the model can be used to explore potential fungal-host population dynamics under a variety of weather conditions. This could be of some value, because if resting spore load and gypsy moth densities are high, the fungus is most likely to control the gypsy moth unless the season is expected to be extremely dry (Weseloh 2002). Various weather scenarios can be explored to gain information about what is likely to happen. The model should also be useful in the further exploration of gypsy 
moth-fungus population ecology. The prevalence of infection output can be used to check that model output is similar to actual fungal prevalence, while the survival output can be used to evaluate fungus effectiveness. Thus, survival data can be derived from disease prevalence data, something that is not usually possible. This ability makes the model output valuable for studying the population dynamics of this system.

Availability. The program runs on Microsoft Windows $C$ and can be downloaded from the Connecticut Agricultural Experiment Station Website (http://www.caes.state.ct.us). The downloaded file (maimaiga.zip) can be uncompressed using WINzip or PKzip. For best results, place the expanded files in a separate directory called \fungus $\backslash$ so the example weather files can be accessed easily. Among the files is "readme.txt", that has detailed information about the model. To run the model, start the file "fungus l.exe". Alternately, a disk with all relevent files and directions for installations is available from the author.

\section{REFERENCES CITED}

Allen, J.C. 1976. A modified sine wave method for calculating degree days. Environ. Entomol. 5: 388-396.

Andreadis, T.G., and R.M. Weseloh. 1990. Discovery of Entomophaga maimaiga in North American gypsy moth, Lymantria dispar. Proc. Natl. Acad. Sci. USA 87: 24612465.

Hajek, A.E. 1999. Pathology and epizootiology of Entomophaga maimaiga infections in forest Lepidoptera. Microb. and Mol. Biol. Rev. 63: 814-835.

Hajek, A.., R.. Humber, J.S. Elkinton, B. May, S. R.A. Walsh, and J.C. Silver. 1990. Allozyme and restriction fragment length polymorphism analyses confirm Entomophaga maimaiga responsible for 1989 epizootics in North American gypsy moth populations. Proc. Natl. Acad. Sci. USA. 87: 6979-6982.

Hajek, A.E., T.S. Larkin, R.1. Carruthers, and R.S. Soper. 1993. Modeling the dynamics of Entomophaga maimaiga (Zygomycetes: Entomophthorales) epizootics in gypsy moth (Lymantria: Lymantriidae) populations. Environ. Entomol. 22: 1172-1187.

Hajek, A.E., R.A. Humber, and J. Elkinton. 1995. Mysterious origin of Entomophaga maimaiga in North America. Amer. Entomol. 41: 31-42.

Weseloh, R.M. 1996. Developing and validating a model for predicting gypsy moth (Lepidoptera: Lymantriidae) defoliation in Connecticut. J. Econ. Entomol. 89: 1546-1555.

Weseloh, R.. 1999. Entomophaga maimaiga (Zygomycete: Entomophthorales) resting spores and biological control of the gypsy moth (Lepidoptera: Lymantriidae). Environ. Entomol. 28: 1162-1171.

Weseloh, R.M. 2002. Modeling the impact of the fungus, Entomophaga maimaiga (Zygomycetes: Entomophthorales) on gypsy moth (Lepidoptera: Lymantriidae): Incorporating infection by conidia. Environ. Entomol. 31: 1071-1084.

Weseloh, R.M. 2003. Short and Long Range Dispersal in the Gypsy moth (Lepidoptera: Lymantriidae) Fungal Pathogen, Entomophaga maimaiga (Zygomycetes: Entomophthorales). Environ. Entomol. (32:111-122).

Weseloh, R.M., and T.G. Andreadis. 1991. Epizootiology of the fungus Entomophaga maimaiga, and its impact on gypsy moth populations. J. Invert. Path. 59: 133141.

Weseloh, R.M., and T.G. Andreadis. 1992. Mechanisms of transmission of the gypsy moth (Lepidoptera: Lymantriidae) fungus, Entomophaga maimaiga (Entomphthorales: Entomophthoraceae) and effects of site conditions on its prevalence. Environ. Entomol. 21: 901 -906.

Weseloh, R.M., and T.. Andreadis. 2002. Detecting the titer in forest soils of spores of the gypsy moth (Lepidoptera: Lymantriidae) fungal pathogen, Entomophaga maimaiga (Zygomycetes: Entomophthorales). Can. Entomol. 134: 269279.

Weseloh, R.M., T.G.Andreadis, and D.W. Onstad. 1993. Modeling the influence of rainfall and temperature on the phenology of infection of gypsy moth, Lymantria dispar, larvae by the fungus Entomophaga maimaiga. Biol. Control. 3: $311-318$. 
Digitized by the Internet Archive in 2011 with funding from

LYRASIS members and Sloan Foundation 
The Connecticut Agricultural Experiment Station (CAES) prohibits discrimination in all its programs and activities on the basis of race, color, ancestry, national origin, sex, religious creed, age, political beliefs, sexual orientation, criminal conviction record, genetic information, learning disability, present or past history of mental disability, mental retardation or physical disability including but not limited to blindness, or marital or family status. To file a complaint of discrimination, write Director, The Connecticut Agricultural Experiment Station, P.O. Box 1106, New Haven, CT 06504, or call (203) 974-8440. CAES is an equal opportunity provider and employer. Persons with disabilities who require alternate means of communication of program information should contact the Station Editor at (203) 974-8446 (voice); (203) 974-8502 (FAX); or paul.gough@po.state.ct.us (E-mail) 


\section{\$ 4 University of Connecticut Libraries}


